\title{
ERG dependence distinguishes developmental control of hematopoietic stem cell maintenance from hematopoietic specification
}

\author{
Samir Taoudi, ${ }^{1,2,6}$ Thomas Bee, ${ }^{3}$ Adrienne Hilton, ${ }^{1}$ Kathy Knezevic, ${ }^{3}$ Julie Scott, ${ }^{4}$ Tracy A. Willson, ${ }^{1,2}$ \\ Caitlin Collin, ${ }^{1}$ Tim Thomas, ${ }^{1,2}$ Anne K. Voss, ${ }^{1,2}$ Benjamin T. Kile, ${ }^{1,2}$ Warren S. Alexander, \\ John E. Pimanda, ${ }^{3}$ and Douglas J. Hilton ${ }^{1,2}$ \\ ${ }^{1}$ Molecular Medicine Division, The Walter and Eliza Institute of Medical Research, Melbourne, Parkville, Victoria 3052, \\ Australia; ${ }^{2}$ Department of Medical Biology, The University of Melbourne, Melbourne, Parkville, Victoria 3010, Australia; ${ }^{3}$ Lowy \\ Cancer Research Centre, The Prince of Wales Clinical School, University of New South Wales, Sydney 2052, Australia; \\ ${ }^{4}$ Microinjection Services, The Walter and Eliza Institute of Medical Research, Melbourne, Parkville, Victoria 3052, Australia; \\ ${ }^{5}$ Cancer and Haematology Division, The Walter and Eliza Institute of Medical Research, Melbourne, Parkville, Victoria 3052, \\ Australia
}

\begin{abstract}
Although many genes are known to be critical for early hematopoiesis in the embryo, it remains unclear whether distinct regulatory pathways exist to control hematopoietic specification versus hematopoietic stem cell (HSC) emergence and function. Due to their interaction with key regulators of hematopoietic commitment, particular interest has focused on the role of the ETS family of transcription factors; of these, ERG is predicted to play an important role in the initiation of hematopoiesis, yet we do not know if or when ERG is required. Using in vitro and in vivo models of hematopoiesis and HSC development, we provide strong evidence that ERG is at the center of a distinct regulatory program that is not required for hematopoietic specification or differentiation but is critical for HSC maintenance during embryonic development. We show that, from the fetal period, ERG acts as a direct upstream regulator of Gata2 and Runx1 gene activity. Without ERG, physiological HSC maintenance fails, leading to the rapid exhaustion of definitive hematopoiesis.
\end{abstract}

[Keywords: ERG; ETS family transcription factors; Gata2; hematopoietic development; hematopoietic stem cells; Runx1; self-renewal]

Supplemental material is available for this article.

Received November 3, 2010; revised version accepted December 20, 2010.

Hematopoietic development occurs sequentially: First, primitive nucleated erythroid cells are generated in the yolk sac (YS); next, hematopoietic progenitors are formed in both the YS and embryo body, after which hematopoietic stem cells (HSCs) emerge within the aorta-gonadmesonephros (AGM) region; finally, definitive hematopoiesis (self-sustaining lifelong hematopoiesis) is driven by the HSCs in fetal liver and then the bone marrow.

Many critical regulators of hematopoiesis have been identified, the absence of which results in failure of hematopoietic specification or inadequate formation of multipotential progenitors. For example, the transcription factors SCL and RUNX1 are essential for hematopoietic specifica-

${ }^{6}$ Corresponding author.

E-MAIL taoudi@wehi.edu.au; FAX 61-3-9347-0852.

Article published online ahead of print. Article and publication date are online at http://www.genesdev.org/cgi/doi/10.1101/gad.2009211. tion, but are dispensable thereafter (Shivdasani et al. 1995; Okuda et al. 1996; Porcher et al. 1996; Wang et al. 1996; Mikkola et al. 2003; Ichikawa et al. 2004; Chen et al. 2009); absence of GATA2 results in an early/mid-gestation failure of hematopoiesis (Tsai et al. 1994); NOTCH1 is critical for progenitor formation, but is dispensable in the adult (Kumano et al. 2003; Hadland et al. 2004; Mancini et al. 2005); and the acetyltransferase MOZ is critical for the function of fetal HSCs (Thomas et al. 2006). In such cases, it is not possible to resolve whether these factors specifically regulate HSC development or if they are required for general hematopoietic function. At the core of this issue is uncertainty about whether the mechanisms controlling hematopoietic specification, HSC formation, and HSC function are common or if distinct regulatory mechanisms are successively employed.

The transcription factor SOX17 is of particular interest. Removal of Sox17 at various developmental stages has 
shown it to be essential for hematopoiesis until adulthood (Kim et al. 2007), indicating the existence of a regulatory pathway operating during the embryonic-neonatal period but not in the adult. The generation of conditional knockout alleles suggests that some key factors, such as RUNX1 and SCL, are required for hematopoietic specification but not for continued hematopoietic development (Schlaeger et al. 2005; Chen et al. 2009); whether these factors are required later in development-for example, within the context of cooperative pathways-remains unexplored.

Interest has developed regarding the role of the ETS family transcription factors during hematopoietic development; notably FLI1 and ERG, which are predicted to be involved in GATA2/SCL-mediated control of Runx1 expression (Chan et al. 2007; Nottingham et al. 2007; Pimanda et al. 2007b; Landry et al. 2008; Wilson et al. 2009). Given the vital roles played by SCL, RUNX1, and GATA2 during hematopoietic development, it would be expected that ERG and FLI1 are also required; however, knockout models of Fli1 have shown that, although required for normal hematopoietic progenitor formation (Hart et al. 2000; Spyropoulos et al. 2000), absence of FLI1 did not prevent HSC production or sustained definitive hematopoiesis (Masuya et al. 2005).

Use of the $\operatorname{Erg}^{\text {MId } 2}$ mouse line-harboring a loss-offunction Erg allele that fails to transactivate downstream gene expression-revealed that competitive reconstitution by adult HSCs from heterozygous $\left(\mathrm{Erg}^{+/ M I d 2}\right)$ mice was perturbed (Loughran et al. 2008). Given that $\mathrm{Erg}^{+/ \text {Mld } 2}$ mice survive as adults, the importance of ERG for HSC function remains unclear. Erg ${ }^{\text {Mld } 2}$ homozygous (Erg ${ }^{\text {Mld2/Mld2 })}$ mice die at mid-gestation, before the formation of the first HSCs, and thus investigations have been restricted to the heterozygous adult. Because of this, little is known about the role of ERG during development of definitive hematopoiesis.

Here, we present a study that shows that control of hematopoietic specification in the embryo is distinct from fetal HSC regulation. Using the Erg ${ }^{\text {MId2 }}$ mouse model, we studied the role of ERG during hematopoietic development. We show that, in the absence of functional ERG, primitive erythropoiesis occurs, hematopoietic pro- genitor and stem cells are produced, and definitive hematopoiesis is initiated. ERG is shown to be a critical early regulator of fetal HSC maintenance, and is therefore required to sustain definitive hematopoiesis. Moreover, we demonstrate that, in vivo, ERG is a direct upstream regulator of Runx1 and Gata2 expression once hematopoiesis proceeds to the fetal liver, thus identifying a model for a second new wave of Runx1 and Gata2 function that is required beyond hematopoietic specification.

\section{Results}

Preliminary investigations have demonstrated that primitive erythropoiesis was initiated in embryos homozygous for the mutant Erg ${ }^{\text {Mld2 } 2}$ allele (Erg ${ }^{\text {Mld2/MId2 }}$, hereafter referred to as $\mathrm{Erg}^{M / M}$ ) (Loughran et al. 2008). To investigate the requirement of ERG for hematopoietic progression, we analyzed the ability of the following processes to occur without functional ERG: (1) initiation of hematopoiesis through generation of hematopoietic progenitors, (2) HSC formation, and (3) definitive hematopoiesisformation of a self-sustaining hematopoietic hierarchy driven by the HSC.

\section{Hematopoietic specification and differentiation is not ERG-dependent}

To determine whether $\operatorname{Erg}^{M / M}$ embryos correctly initiated hematopoiesis, the number of functional hematopoietic progenitors (culture colony forming units [CFUCs]) was quantified. Cell suspensions of embryonic day 8.5 (E8.5) YS and embryo proper were cultured in methylcellulose-based medium to produce hematopoietic colonies. Although few CFU-Cs were detected in the embryo proper, their numbers were comparable on mutant and wild-type backgrounds (Fig. 1A). Likewise, in the YS, CFU$\mathrm{C}$ content was unaffected by mutation of Erg, with expected numbers of primitive erythroid CFU-Cs (CFU-EryPs), burstforming unit-erythroids (BFU-Es), CFU-Masts, and CFUmacrophages (CFU-Macs) detected (Fig. 1B).

Between E8.5 and E9.5, primitive erythropoiesis declines; CFU-EryPs are lost, but primitive erythroid cells

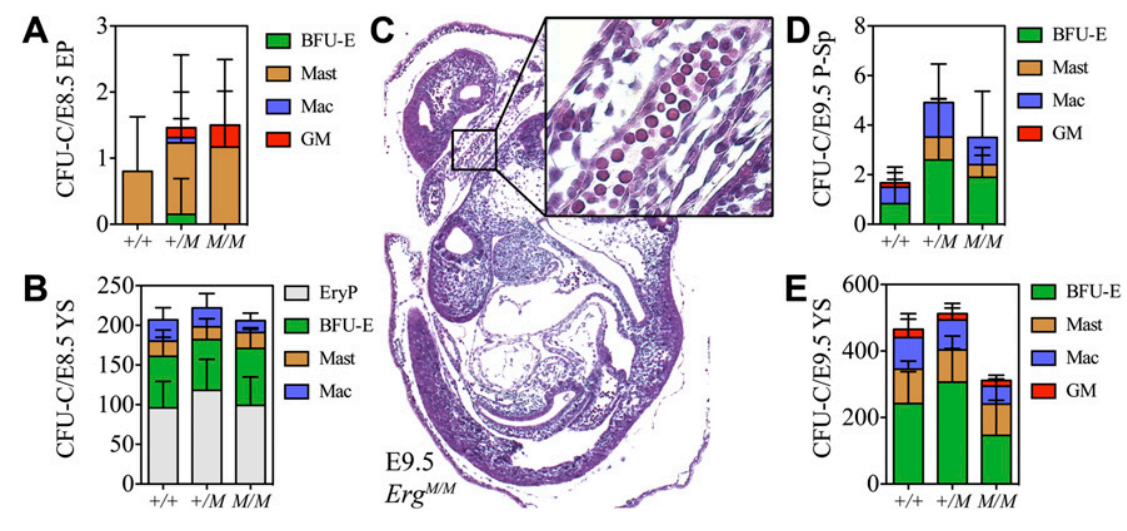

Figure 1. Hematopoietic specification occurs without functional ERG. The number and class of CFU-Cs present in E8.5 embryo proper $(\mathrm{EP})(A)$ and E8.5 YS $(B) .(C)$ Sagittal section through an E9.5 embryo stained with hematoxylin and eosin (original magnification, $\times 50)$. Inset is a high-magnification $(\times 400)$ enlargement of the boxed region demonstrating the presence of primitive erythroid cells passing through the umbilical cord between the placenta and embryo proper. The number and class of CFU-Cs present in E9.5 para-aortic splanchnopleura (P-Sp) (D) and E9.5 YS $(E)$. Data are cumulative of five independent experiments. (BFU-E) Burst-forming uniterythroid; (GM) CFU-granulocyte/macrophage; (Mast) CFU-Mast; (Mac) CFU-macrophage; (EryP) CFU-primitive erythroid. 
remain present in the peripheral circulation, while CFUCs become more frequent in the embryo proper. As in the wild type (data not shown), we observed large nucleated primitive erythroid cells in peripheral circulation of the E9.5 $\mathrm{Erg}^{\mathrm{M} / \mathrm{M}}$ embryo (Fig. 1C) and found no differences in CFU-C number or differentiation capacity between $\mathrm{Erg}^{+/+}$ and $E r g^{M / M}$ para-aortic splanchnopleura or YS (Fig. 1D,E). Thus, ERG was not required for hematopoietic specification, progenitor cell formation, or hematopoietic differentiation to occur.

\section{Functional ERG is not required for intraaortic cluster (IAC) formation}

Given that hematopoietic specification occurred on the $\mathrm{Erg}^{\mathrm{M}}$ background, we investigated the impact of the mutant allele on HSC formation. Emergence of the first HSC in the embryo occurs in close association with the arterial system. This process is initiated in the ventral aspect of the dorsal aorta (Ao) of the E10.5 AGM region and is thought to manifest as the formation of hematopoietic IACs (Medvinsky and Dzierzak 1996; de Bruijn et al. 2000; Bertrand et al. 2005; Taoudi and Medvinsky 2007; Taoudi et al. 2008). In the mouse, the evidence suggests that IACs form by cells budding from the endothelial lining of the Ao; the resulting cells maintain endothelial markers (such as VE-cadherin) and begin expressing hematopoietic markers, including CD45 and CD41 (Bertrand et al. 2005; Corbel et al. 2005; Boisset et al. 2010). At E11.5, the VE-cadherin ${ }^{+} \mathrm{CD} 45^{+}$population contains pre-HSCs and the first HSC (North et al. 2002; Taoudi et al. 2005, 2008; McKinney-Freeman et al. 2009).

The maximal capacity of the AGM region to generate HSCs occurs at E11.5 (Kumaravelu et al. 2002), at which stage we observed intense Erg expression within the Ao and IACs of the $\mathrm{Erg}^{+/+}$AGM (Fig. 2A). To identify which cells expressed Erg, E11.5 AGM cells were purified into endothelial (VE-cadherin ${ }^{+} \mathrm{CD}^{-} 5^{-}$), hematopoietic progenitor/committed lineage (VE-cadherin ${ }^{-} \mathrm{CD}^{4} 5^{+}$), and pre-HSC/ HSC (VE-cadherin ${ }^{+} \mathrm{CD} 45^{+}$) populations by flow cytometry, and relative Erg expression was determined by quantitative real-time PCR. We found that Erg was expressed at significantly higher levels in the endothelial and pre-HSC/HSC fractions than in the progenitor/committed lineage population $(P<0.005)$ (Fig. 2B). ERG was also detected at the protein level within E11.5 AGM IACs by confocal microscopy (Supplemental Fig. 1A,B). These data suggest that, within the hematopoietic lineage, ERG might be involved in HSC emergence.

At E10.5, $\mathrm{Erg}^{\mathrm{M} / \mathrm{M}}$ embryos were observed at the expected frequency and exhibited little evidence of developmental defects; however, by E11.5, no viable $\operatorname{Erg}^{M / M}$ embryos were observed. To eliminate the influence of embryonic lethality on our analyses, only viable E10.5 embryos were used. Flow cytometric analysis of E10.5 AGM regions demonstrated that cells coexpressing CD45, VE-cadherin, and CD41 were present in both the $\mathrm{Erg}^{+/+}$and $\mathrm{Erg}^{\mathrm{M} / \mathrm{M}}$ AGM regions (Fig. 2C,D). To confirm that IACs were formed, transverse sections of E10.5 AGM were studied. We observed no quantitative difference in either
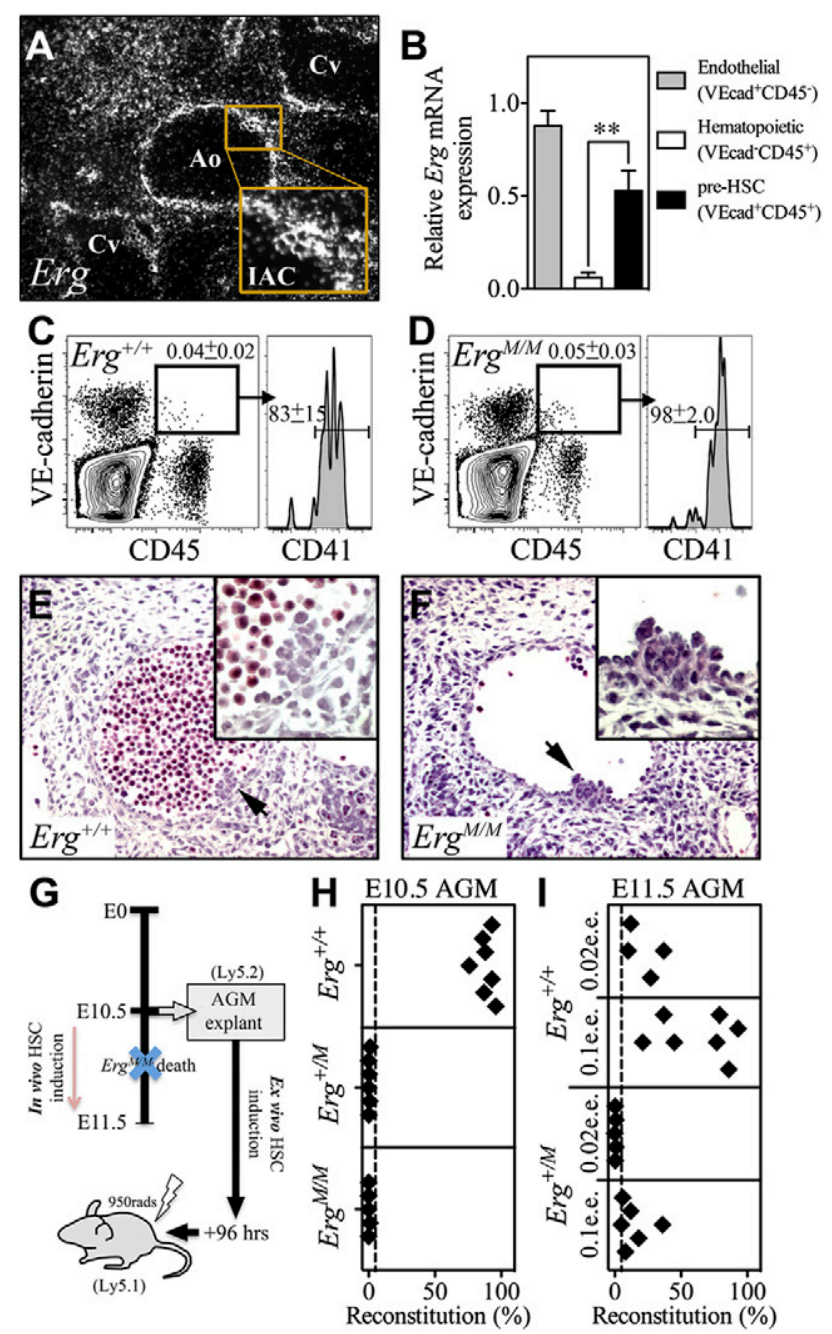

Figure 2. Functional HSCs are not generated in the $\operatorname{Erg}^{M / M}$ AGM region. (A) Representative images of radioactive in situ hybridization with an antisense probe revealing Erg expression in a transverse section of the E11.5 AGM region (original magnification, $\times 400$ ); Erg is highly expressed in the Ao, cardinal veins $(\mathrm{Cv})$ and IACs. $(B)$ Quantitative real-time PCR results for cells purified from the E11.5 AGM region demonstrating the level of Erg expression in VEcadherin (VE-cad) ${ }^{+} \mathrm{CD} 45^{-}$endothelial cells, VE-cad ${ }^{-} \mathrm{CD} 45^{+}$committed hematopoietic cells, and the VE-cad ${ }^{+} \mathrm{CD} 45^{+}$pre-HSC/HSC population. Data are cumulative of $n=4$ experiments; values were normalized to levels of the Hmbs-1 housekeeper. Representative contour plots showing that VE-cadherin ${ }^{+} \mathrm{CD} 45^{+}$cells are formed in the $\mathrm{Erg}^{+/+}(C)$ and $\operatorname{Erg}^{M / M}(D)$ E10.5 AGM; these cells also coexpress the early hematopoietic marker CD41. Representative transverse sections from E10.5 $\mathrm{Erg}^{+/+}$AGM $(E)$ and $\operatorname{Erg}^{M / M}$ AGM $(F)$. IACs are indicated by arrows, and enlargements of highlighted clusters are inset; of note, the absence of blood within the lumen of $\mathrm{Erg}^{\mathrm{M} / \mathrm{M}}$ is not specific to the mutant Erg allele, but represents a variation noted even among sections of individual wild-type AGM regions. $(G)$ Schematic representation of the organ explant strategy used to circumvent the peri-E11.5 embryonic lethality of the $\mathrm{Erg}^{\mathrm{M} / \mathrm{M}}$ phenotype, so enabling the study of HSC formation ex vivo. $(H)$ Sixteen-week reconstitution data from 96-h explanted E10.5 AGM; each recipient received a 0.2 e.e. dose of AGM. (I) Sixteen-week reconstitution data from 96-h explanted E11.5 AGM; each recipient received either a 0.1 e.e. or 0.02 e.e. dose of AGM. Dashed line represents the threshold level for high-level reconstitution. 
large or small IACs in each of the genotypes (Fig. 2E,F), indicating that, in the absence of functional ERG, pre-HSC formation was initiated.

The death of $\operatorname{Erg}^{M / M}$ embryos between E10.5 and E11.5 precludes investigation into the pre-HSC-to-HSC transition in vivo; however, this crucial process can be recapitulated ex vivo using the organ explant technique (Medvinsky and Dzierzak 1996; de Bruijn et al. 2000; Kumaravelu et al. 2002; Taoudi and Medvinsky 2007). Addition of exogenous growth factors (IL3, SCF, and Flt3 ligand) during explant culture enables extensive generation of HSCs from E11.5 AGM explants (Taoudi et al. 2008). Accordingly, AGM regions were dissected from healthy E10.5 embryos and cultured as explants under these conditions for $96 \mathrm{~h}$. If capable, $\mathrm{Erg}^{\mathrm{M} / \mathrm{M}}$ AGM regions should yield HSCs capable of contributing to hematopoiesis following transplant of explants into irradiated adult recipients (Fig. 2G). To assess HSC emergence, 0.2 embryo equivalents (e.e.) of cultured explant were transplanted into lethally irradiated adults; if HSCs were generated, this dose would give rise to high-level multilineage hematopoietic reconstitution. After $16 \mathrm{wk}$, recipients were analyzed for evidence of donor AGM-derived hematopoietic contribution. Strikingly, all recipients $(n=7)$ of $\mathrm{Erg}^{+/+}$ AGM explants were reconstituted at high levels $(88 \% \pm$ $2.5 \%)$, whereas none of the recipients of $\mathrm{Erg}^{+/ M}(n=6)$ or $\mathrm{Erg}^{\mathrm{M} / \mathrm{M}}(\mathrm{n}=7)$ AGM explants were successfully reconstituted $(0.4 \% \pm 0.2 \%$ and $0.2 \% \pm 0.2 \%$, respectively) (Fig. 2H).

To investigate if a developmental delay in HSC formation could account for the inability of mutant AGM regions to generate transplantable HSCs, we performed organ explant transplantation experiments using E11.5 AGM from $\mathrm{Erg}^{+/+}$and $\mathrm{Erg}^{+/ M}$ embryos ( $\mathrm{Erg}^{\mathrm{M} / \mathrm{M}}$ embryos were not used, having died by E11.5). All mice that received 0.1 e.e. $(n=5)$ or 0.02 e.e. $(n=4)$ doses of $\mathrm{Erg}^{+/+}$explants were reconstituted at high levels $(52 \% \pm 11 \%$ and $22 \% \pm$ $6.4 \%$, respectively) (Fig. 2I), indicating that $\geq 50$ HSCs were generated per AGM. From the cohort of $\mathrm{Erg}^{+/ M}$ recipients, only those that received a 0.1 e.e. dose were successfully reconstituted $(14 \% \pm 11 \%, n=7)$ (Fig. $2 \mathrm{I})$, indicating that $<50$ HSCs were produced. These data suggest that either the emergence or function of HSCs was diminished in $\mathrm{Erg}^{+/ M}$ AGM regions.

\section{CFU-C expansion is not maintained in the absence of ERG}

The inability of mutant cells to successfully reconstitute adult recipients does not necessarily reflect the failure of HSC emergence but might be secondary to defects in HSC function, such as niche engraftment, self-renewal, or differentiation. To gain insight into possible causes of hematopoietic failure, we investigated the ability of the $\mathrm{Erg}^{M / M}$ embryo to sustain hematopoiesis.

Between E8.5 and E10.5, both the $\mathrm{Erg}^{+/+}$and $\mathrm{Erg}^{+/ \mathrm{M}}$ YS supported concomitant hematopoietic differentiation and CFU-C expansion (Fig. 3A,B). During the same period of time, production of $\mathrm{CD} 45^{+}$cells in the $\mathrm{Erg}^{\mathrm{M} / \mathrm{M}}$ YS occurred as expected but the CFU-C population failed to
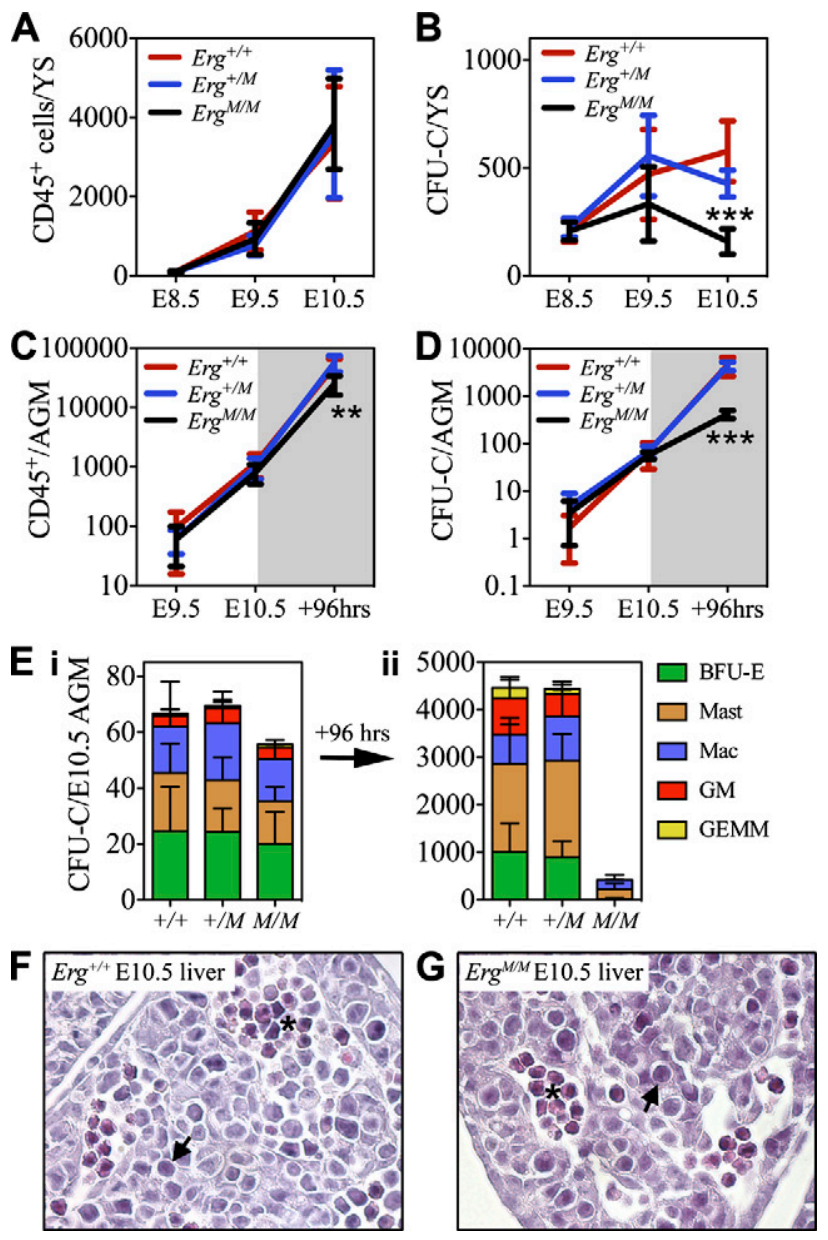

Figure 3. Multipotential $\operatorname{Erg}^{M / M} \mathrm{CFU}-\mathrm{Cs}$ fail to sustain expansion. Changes in the absolute number of hematopoietic $\left(\mathrm{CD}^{+} 5^{+}\right)$ cells $(A)$ and functionally defined CFU-C numbers $(B)$ in the E8.5E10.5 YS $\left(\mathrm{Erg}^{+/+}, n=6 ; \mathrm{Erg}^{+/ M}, n=13 ; \mathrm{Erg}^{M / M}, n=6\right)$. Quantification of changes in $\mathrm{CD}^{+} 5^{+}$cell numbers $(C)$ and CFU-Cs $(D)$ in fresh P-Sp/AGM region between E9.5-E10.5 and following 96-h explant culture of E10.5 AGM $\left(\mathrm{Erg}^{+/+}, n=6 ; \mathrm{Erg}^{+/ M}, n=13 ; \mathrm{Erg}^{\mathrm{M} / \mathrm{M}}\right.$, $n=10) .(E)$ CFU-C classes present in fresh E10.5 AGM (panel $i$ ) and following 96-h explant culture (panel ii); data are cumulative of five independent experiments. Representative images of transverse sections from E10.5 liver of $\operatorname{Erg}^{+/+}(F)$ and $\operatorname{Erg}^{M / M}(G)$ embryos; blast cells are indicated by arrows, and erythroid clusters are indicated by an asterisk. Original magnification, $\times 400 .\left(^{*}\right) P<$ 0.05; $\left.\left.\left.\right|^{\star \star}\right) P<0.01 ;\left.\right|^{\star \star \star}\right) P<0.001$.

expand, resulting in the presence of significantly fewer CFU-Cs at E10.5 compared with $\mathrm{Erg}^{+/+}$controls $(P<$ 0.001) (Fig. 3B). These data suggest that ERG might be required for progenitor self-renewal.

Contrary to observations in the YS, between E9.5 and E10.5, production of CD45 cells and CFU-Cs in the $\mathrm{Erg}{ }^{\mathrm{M} / \mathrm{M}}$ AGM region was comparable with $\mathrm{Erg}^{+/+}$and $\mathrm{Erg}^{+/ M}$ AGM regions (Fig. 3C-E, panel i). The ability of $E r g^{M / M}$ AGM to preserve CFU-Cs in vivo provided the opportunity to test the hypothesis that, in the absence of functional ERG, hematopoietic differentiation occurs but progenitors fail to effectively self-renew. To this end, E10.5 AGM regions were cultured as explants for $96 \mathrm{~h}$ under conditions that 
facilitate an acute burst of simultaneous hematopoietic differentiation, CFU-C expansion, and HSC generation (Taoudi et al. 2008). The ability of the AGM to sustain hematopoiesis was assessed according to the number of post-explant $\mathrm{CD} 45^{+}$cells and CFU-Cs.

Although the number of $\mathrm{CD}^{4} 5^{+}$cells following explant culture of $\mathrm{Erg}^{\mathrm{M} / \mathrm{M}}$ AGM (which increased from $600 \pm 81$ to $25,005 \pm 3620)$ was significantly less $(P<0.01)$ than observed in the $\mathrm{Erg}^{+/+}$AGM (from $1142 \pm 156$ to $49,967 \pm$ 4293) (Fig. 3C), the fold expansion was comparable (41fold and 43-fold, respectively). Following explant, the $\mathrm{Erg}^{\mathrm{M} / \mathrm{M}}$ CFU-C number increased sevenfold (from $57 \pm$ 9 to $419 \pm 36)$ (Fig. 3D); this was significantly less $(P<$ $0.0001)$ than the 67-fold expansion observed from $\mathrm{Erg}^{+/+}$ AGM and the 65-fold expansion from $\mathrm{Erg}^{+/ M}$ AGM. Importantly, unlike the expansion of all CFU-C classes observed from $\mathrm{Erg}^{+/+}$and $\mathrm{Erg}^{+/ M}$ AGM regions, $\mathrm{Erg}^{\mathrm{M} / \mathrm{M}}$ CFU-C expansion was exclusively of unipotent CFUMast and CFU-Mac; all other progenitors were lost (Fig. $3 \mathrm{E}$, panel ii), indicating that, although $\operatorname{Erg}^{\mathrm{M} / \mathrm{M}}$ could undergo rapid hematopoietic differentiation, $\operatorname{Erg}^{M / M}$ multipotential progenitors were unable to sustain expansion. Of note, no difference in viability was detected in cells from $\mathrm{Erg}^{+/ M}$ or $E r g^{M / M}$ AGM regions before or after culture (as judged by Trypan blue exclusion and 7-AAD staining) (data not shown). We also observed no significant difference in the frequency of cells undergoing apoptosis in progenitor-enriched populations from E9.5-E10.5 YS, E10.5 AGM, or E10.5 livers from embryos containing the mutant Erg allele (Supplemental Fig. 2A,B).

To investigate whether $\operatorname{Erg}^{M / M}$ cells were capable of homing to secondary hematopoietic organs in vivo, an essential process during hematopoietic development, we studied hematopoiesis in the liver and placenta. The presence of blast-like cells, erythroid clusters, and CD45 ${ }^{+}$ cells in the $\mathrm{Erg}^{\mathrm{M} / \mathrm{M}} \mathrm{E} 10.5$ liver was similar to that observed in the $\mathrm{Erg}^{+/+}$liver (Fig. 3F,G; Supplemental Fig. 3A). Normal numbers of $\mathrm{CD} 45^{+}$cells were also found in the $\operatorname{Erg}^{M / M}$ E10.5 placenta (Supplemental Fig. 3B), indicating that seeding and hematopoietic differentiation in secondary hematopoietic organs occurred in the absence of ERG.

$\mathrm{Erg}^{\mathrm{M} / \mathrm{M}}$ cells transiently contribute

to fetal hematopoiesis

Given that hematopoietic progenitor formation, differentiation, and seeding of secondary organs appeared to be relatively normal in $\mathrm{Erg}^{M / M}$ mutant embryos, we considered that the failure of mutant AGM regions to reconstitute adult mice in transplantation assays might arise from inadequate HSC self-renewal. To test whether $\mathrm{Erg}^{\mathrm{M} / M}$ cells were able to sustain hematopoiesis during fetal development, and to address the question of how ERG contributes to HSC formation and maintenance under physiological conditions, we created and analyzed embryo chimeras. Chimeras were produced by morula aggregation: Each $\mathrm{GFP}^{-}$embryo on an $\mathrm{Erg}^{+/+}$background was aggregated with a $\mathrm{GFP}^{+}$embryo on either an $\mathrm{Erg}^{+/+}, \mathrm{Erg}^{+/ M}$, or $\mathrm{Erg}^{\mathrm{M} / \mathrm{M}}$ background (GFP was expressed under the control of the human ubiquitin C promoter) (Schaefer et al. 2001).
Following blastocyst formation in vitro, development was allowed to proceed following transfer to pseudopregnant females; chimeras were analyzed at E14.5 or E18.5, or as adults (Fig. 4A, panel i). To provide a measure of overall chimerism, independent of the hematopoietic system, primary fibroblasts were derived from each of the chimeras; following purification by flow cytometry, these cells were used to determine both the degree of chimerism and the genotype of the GFP ${ }^{+}$embryo.

$\mathrm{Erg}^{\mathrm{M} / \mathrm{M}}$ fibroblasts were readily derived at each of the stages analyzed (Fig. 4A, panel ii). The ability of $\mathrm{Erg}^{\mathrm{M} / \mathrm{M}}$ cells to contribute to major nonhematopoietic organs was confirmed by fluorescence microscopy; in each chimera, $\operatorname{Erg}^{M / M}$ cells contributed to brain, heart, kidney, liver, lung, and skeletal muscle (Fig. 4A, panel iii; data not shown). Importantly, the extent of organ chimerism closely reflected the overall chimerism observed in primary fibroblasts. To limit the influence of overall chimerism when assessing hematopoietic contribution (i.e., to allow comparative analysis of animals with different levels of overall chimerism), the hematopoietic contribution of each chimera was scored as a normalized ratio relative to overall chimerism, a normalized hematopoietic contribution (nhc). An nhc score of 1.0 occurs when hematopoietic contribution is equal to overall chimerism, and a score of 0.0 occurs with no observed hematopoietic contribution.

At E14.5, contribution of $\mathrm{Erg}^{\mathrm{M} / \mathrm{M}}$ cells to the peripheral blood (PB) of $\left[\mathrm{Erg}^{+/+}: \mathrm{Erg}^{\mathrm{M} / \mathrm{M}}\right]$ chimeras was as effective as that observed in $\left[\mathrm{Erg}^{+/+}: \mathrm{Erg}^{+/+}\right]$and $\left[\mathrm{Erg}^{+/+}: \mathrm{Erg}^{+/ M}\right]$ chimeras (Fig. 4B). $\operatorname{Erg}^{M / M}$ cells also contributed to hematopoiesis in the liver (Fig. 4C), which at E14.5 is the major hematopoietic organ of the embryo (Ema and Nakauchi 2000; Kumaravelu et al. 2002; Gekas et al. 2005). In contrast to $\mathrm{Erg}^{+/+}$and $\mathrm{Erg}^{+/ M}$ hematopoietic cells, which maintained a contribution at E18.5, $\operatorname{Erg}^{M / M}$ cells were almost undetectable in the E18.5 liver (nhc $=0.06 \pm 0.03$ ) (Fig. 4C), yet contributed to erythroid cells (data not shown) and leukocytes in $\mathrm{PB}$ (nhc $=0.16 \pm 0.15)$ (Fig. 4B) and thymic lymphoid cells $(\mathrm{nhc}=0.41 \pm 0.24)$ (Fig. 4E-G), albeit less effectively than either $\mathrm{Erg}^{+/+}$or $\mathrm{Erg}^{+/ M}$ cells, indicating that $\mathrm{Erg}^{\mathrm{M} / \mathrm{M}}$ cells could undergo multilineage differentiation. Examination of chimeric adult bone marrow confirmed that $\operatorname{Erg}^{M / M}$ cells could not sustain hematopoietic contribution $(\mathrm{nhc}=0$ ) (Fig. $4 \mathrm{D})$. Of note, the contribution of $\mathrm{Erg}^{+/ M}$ cells to all adult hematopoietic organs was very low (nhc $=0.05 \pm 0.03$ ) (Fig. 4B-G), indicating a dose-dependent function of ERG for sustaining hematopoiesis.

Between E15.5 and E18.5, the bone marrow is seeded by hematopoietic progenitors and HSCs (Christensen et al. 2004; Gekas et al. 2005), signifying the onset of medullary hematopoiesis. No significant difference in the contribution to chimeric E18.5 bone marrow was observed between $\mathrm{Erg}^{+/+}$and $\mathrm{Erg}^{+/ M}$ cells (nhc $=0.96 \pm 0.12$ and $0.77 \pm 0.2$, respectively) (Fig. 4D; Supplemental Fig. 4). The contribution of $\operatorname{Erg}^{M / M}$ hematopoietic cells to E18.5 bone marrow was low but equivalent to that in the E18.5 liver (nhc $=0.08 \pm 0.05$ ) (Fig. 4C,D; Supplemental Fig. 4), indicating that failure of hematopoietic contribution to the adult did not arise from a seeding defect. 


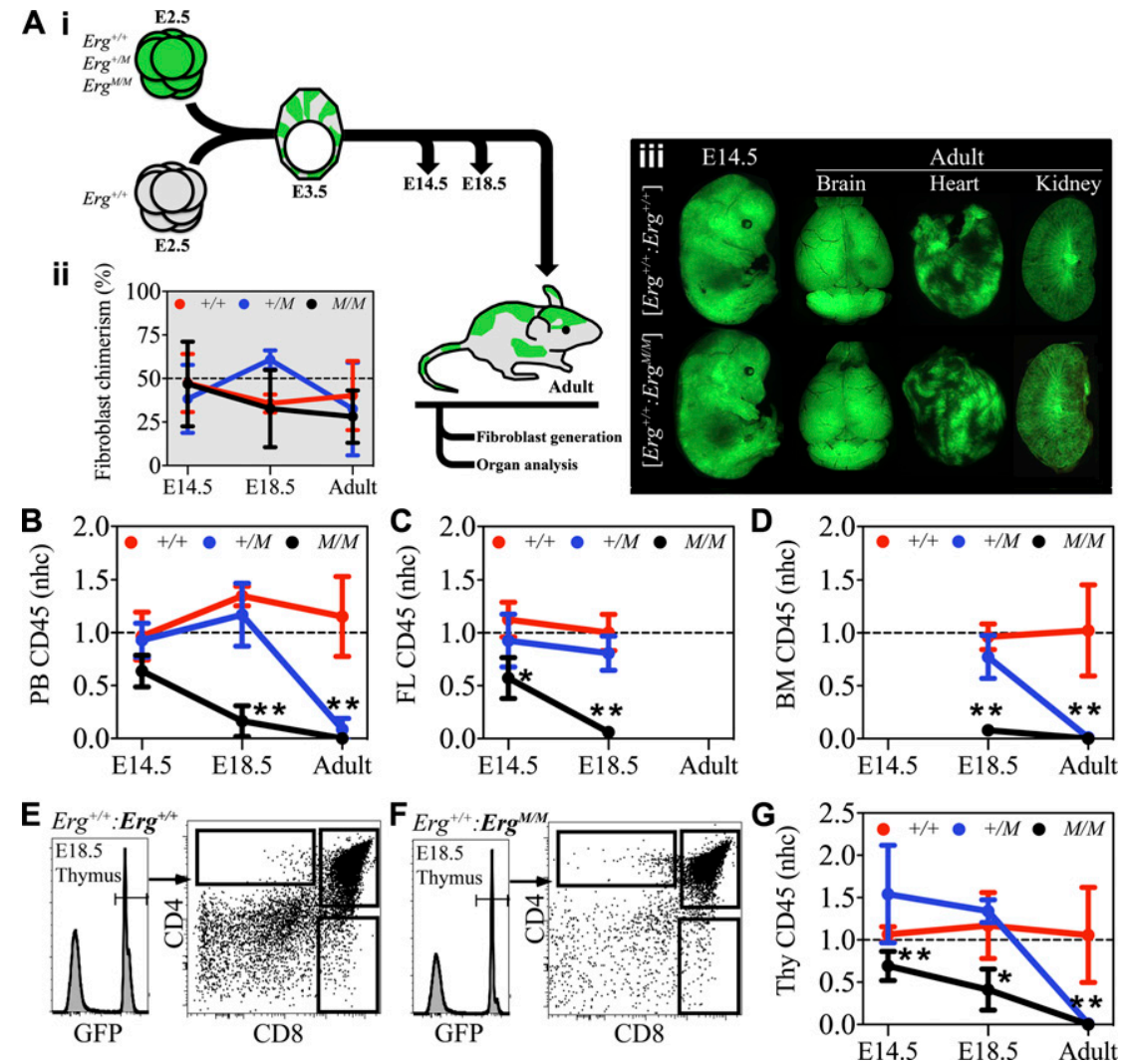

Figure 4. $\operatorname{Erg}^{M / M}$ cells transiently contribute to fetal hematopoiesis. (A, panel i) Schematic representation of the chimera generation experimental strategy. (Panel ii) Percentage contribution of $\mathrm{GFP}^{+}$donor embryos to fibroblast populations at E14.5, E18.5, and adulthood, providing a quantitative measure of nonhematopoietic chimerism used as a reference to calculate an nhc score. (Panel iii) Composite of representative fluorescence images illustrating the capacity of $\mathrm{Erg}^{+/+}, \mathrm{Erg}^{+/ M}$, and $\mathrm{Erg}^{\mathrm{M} / \mathrm{M}}$ embryos to contribute to nonhematopoietic organs in chimeras. nhe scores of $\mathrm{GFP}^{+}$ embryos to $\mathrm{CD} 45^{+}$cells in $\mathrm{PB}(B)$, fetal liver $(C)$, and bone marrow $(D)$. Representative flow cytometric analysis of chimerism in E18.5 fetal thymi contributed to by $\mathrm{GFP}^{+} \mathrm{Erg}^{+/+}(E)$ and $\mathrm{GFP}^{+} \mathrm{Erg}^{\mathrm{M} / \mathrm{M}}(F)$ donor embryos. $(G)$ nhc scores of $\mathrm{GFP}^{+}$embryos to CD45 $5^{+}$thymocytes. Data are cumulative of three to five independent experiments: E14.5 $\mathrm{Erg}^{+/+}(n=6), \mathrm{Erg}^{+/ M}$ $(n=9)$, and $\operatorname{Erg}^{M / M}(n=5)$; E18.5 $\mathrm{Erg}^{+/+}(n=5)$, $\operatorname{Erg}^{+/ M}(n=7)$, and $\operatorname{Erg}^{M / M}(n=4)$; and adult $\operatorname{Erg}^{+/+}(n=6), \operatorname{Erg}^{+/ M}(n=8)$, and $\operatorname{Erg}^{M / M}(n=5)$. Plots represent mean $\pm \mathrm{SD} .\left(^{\star}\right) P<0.02 ;\left({ }^{\star \star}\right)$ $P<0.0001$. (Thy) Thymus; (FL) fetal liver; (BM) bone marrow.

\section{ERG is critical for physiological HSC maintenance}

The inability of $\operatorname{Erg}^{M / M}$ cells to sustain hematopoietic contribution could be caused by failure of HSC formation or reflect failure of HSC self-renewal, so definitive hematopoiesis was initiated but not sustainable. We therefore investigated the ability of $\mathrm{Erg}^{\mathrm{M} / M}$ cells to contribute to the fetal HSC population. From E14.5 until adulthood, HSCs can be prospectively identified at high frequency by the SLAM-LSK immunophenotype: absent/low expression of most lineage markers (including CD41 and CD48) and the coexpression of CD150, c-Kit, and Scal (Kiel et al. 2005, 2008; Kim et al. 2006; McKinney-Freeman et al. 2009). Between E14.5 and E18.5, HSCs undergo continuing expansion while supporting extensive hematopoietic differentiation; thus, the HSC population must be capable of both maintaining and expanding self-renewals. These dynamics provide an ideal platform to assess HSC selfrenewal in a physiological setting. To this end, we analyzed chimeric livers and bone marrow for the contribution of $\mathrm{GFP}^{+}$cells to the HSC population according to the SLAMLSK immunophenotype; successful ongoing hematopoiesis was assessed by the contribution to lineage-positive $\left(\mathrm{Lin}^{+}\right)$ hematopoietic cells.

The contribution by $\mathrm{Erg}^{+/+}$cells to HSCs was maintained from E14.5 until adulthood $(\mathrm{nhc}=1.10 \pm 0.30$ and $0.92 \pm 0.37$, respectively) (Fig. $5 \mathrm{~A}-\mathrm{D}$ ). $\mathrm{Erg}^{+/ M}$ cells robustly contributed to E14.5 HSCs but were less effective than wild-type controls $(\mathrm{nhc}=0.69 \pm 0.20, P<0.01)$. This contribution remained stable until E18.5 (nhc $=0.46 \pm$
0.23), however; by adulthood, the contribution of $\mathrm{Erg}^{+/ M}$ cells to the HSC compartment was vanishingly low $(\mathrm{nhc}=0.01 \pm 0.01)($ Fig. $5 \mathrm{~A}-\mathrm{D})$. Although $\mathrm{Erg}^{\mathrm{M} / \mathrm{M}}$ cells were clearly able to generate HSCs, their contribution at E14.5 was already poor $(\mathrm{nhc}=0.18 \pm 0.09)$ (Fig. 5A,D) and, from E18.5 onward, no $\operatorname{Erg}^{M / M}$ HSCs were detectable (Fig. 5B-D). Interestingly, between E14.5 and E18.5, loss of contribution to $\mathrm{Lin}^{+}$cells by $\mathrm{Erg}^{+/ M}$ and $\mathrm{Erg}^{\mathrm{M} / \mathrm{M}}$ donor embryos was preceded by a rapid decline in mutant HSCs (Fig. 5E). The presence of $\mathrm{Erg}^{+/ M}$ HSCs in E18.5 chimeric bone marrow indicated that the inability to sustain a high-level hematopoietic contribution was not caused by failure of HSC seeding (Supplemental Fig. 5).

\section{ERG is a direct upstream regulator of Gata2 and Runx1 expression in vivo}

Our analyses of Erg mutant and chimeric embryos suggested that ERG was essential for sustaining hematopoiesis by regulating self-renewal, but not for de novo generation, seeding, or differentiation of HSCs. We next sought a molecular explanation for the important function of ERG. Investigating Erg expression in wild-type embryos by quantitative real-time PCR revealed that, although expressed at a low level, Erg was expressed significantly higher $(P<0.05)$ in the E11.5 liver progenitor-enriched population (Fig. 6A) and E14.5 fetal liver HSCs (SLAMLSK) (Fig. 6B) than in lineage-committed hematopoietic cells, suggesting that ERG may influence transcriptional regulation within the progenitor/stem cell compartments. 


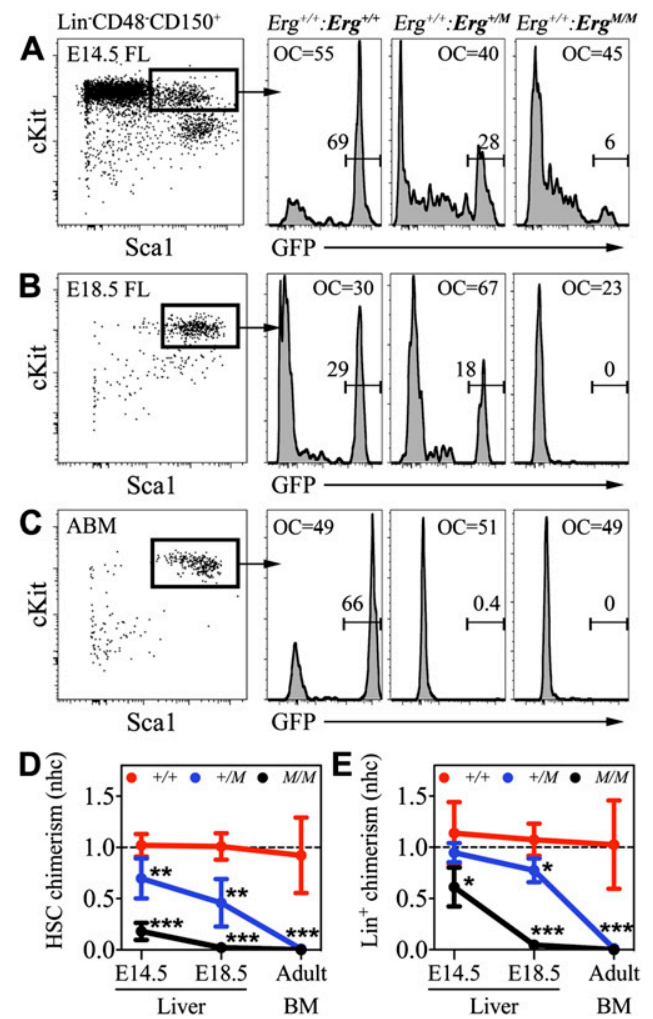

Figure 5. ERG is critical for HSC maintenance. Representative examples of $\mathrm{GFP}^{+}$contribution to SLAM-LSK-defined HSC populations in chimeric E14.5 liver $(A)$, E18.5 liver $(B)$, and adult bone marrow $(C)$. Quantification of normalized hematopoietic chimerism by $\mathrm{GFP}^{+}$embryos to HSC (SLAM-LSK) (D) and lineage ${ }^{+}\left(\operatorname{Lin}^{+}\right)(E)$ populations in fetal liver (E14.5 and E18.5) and adult bone marrow. Data are cumulative of three to five independent experiments: $\operatorname{Erg}^{+/+}(n=6), \operatorname{Erg}^{+/ M}(n=9)$, and $\operatorname{Erg}^{M / M}(n=5) ; E 18.5 \mathrm{Erg}^{+/+}(n=5), \operatorname{Erg}^{+/ M}(n=7)$, and $\operatorname{Erg}^{M / M}$ $(n=4)$; and adult $\mathrm{Erg}^{+/+}(n=6) \mathrm{Erg}^{+/ M}(\mathrm{n}=8)$, and $\mathrm{Erg}^{M / M}(\mathrm{n}=5)$. For reference, overall chimerism $(\mathrm{OC})$ is indicated. Plots represent mean $\pm \mathrm{SD} .\left(^{\star}\right) P<0.03$; $\left.\left.\left.\right|^{\star \star}\right) P<0.01 ;\left.\right|^{\star \star \star}\right) P<0.0001$.

Little is known about the in vivo mechanisms of ERG action. It has been suggested that ERG acts in concert with the "triad" of transcription factors SCL, GATA2, and FLI1 (Chan et al. 2007; Pimanda et al. 2007b; Landry et al. 2008; Wilson et al. 2009, 2010), with these factors thought to regulate Runx1 expression (Nottingham et al. 2007). At E10.5, hematopoiesis occurred normally in the $\mathrm{Erg}^{M / M}$ liver (Fig. 3G; Supplemental Fig. 3A); thus, we used the E10.5 liver to investigate whether loss of ERG affects the expression of Fli1, Gata2, and Scl. Given that these triad factors establish an autoregulatory loop (Pimanda et al. $2007 \mathrm{~b}$ ), we were interested in investigating whether loss of ERG function would disrupt their expression.

Of the triad factors, only the expression of Gata2 was significantly decreased; this was Erg dose-dependent and resulted in a $48 \%$ decrease in Gata2 expression in the $\mathrm{Erg}^{+/ M}$ liver and a $81 \%$ decrease in the $\mathrm{Erg}^{\mathrm{M} / \mathrm{M}}$ liver (Fig. 6C). In the E9.5-E10.5 AGM, NOTCH1 regulates Gata2 expression (Robert-Moreno et al. 2005, 2008). We therefore investigated if reduced Gata2 expression in the E10.5 liver could be attributed to a loss in Notch1 expression. From E10.5 liver, we observed no significant difference in Notch1 expression between the genotypes (Fig. 6C), indicating that NOTCH1 was not sufficient to drive Gata2 expression in mutant embryos.

Runx1 knockout studies have demonstrated that, after hematopoietic specification, RUNX1 is no longer required for continued hematopoietic development (Okuda et al. 1996; Wang et al. 1996; Ichikawa et al. 2004; Chen et al. 2009), but Runx1 is expressed by HSCs in the AGM region and the fetal liver (North et al. 2002). Given that little is known about the cooperative requirement for transcription factors during hematopoietic development, we speculated that suboptimal expression of Gata2 in $E r g^{M / M}$ fetal liver would be accompanied by loss of other requisite factors (such as RUNX1), and that a compound loss of essential regulators might underlie the $\mathrm{Erg}^{\mathrm{M} / \mathrm{M}}$ HSC failure. Interestingly, we found that Runx1 expression was significantly reduced $(P<0.01)$ : Runx1 was reduced by $35 \%$ in the $\mathrm{Erg}^{+/ M}$ liver and by $57 \%$ in the $\mathrm{Erg}^{\mathrm{M} / \mathrm{M}}$ liver (Fig. 6C).
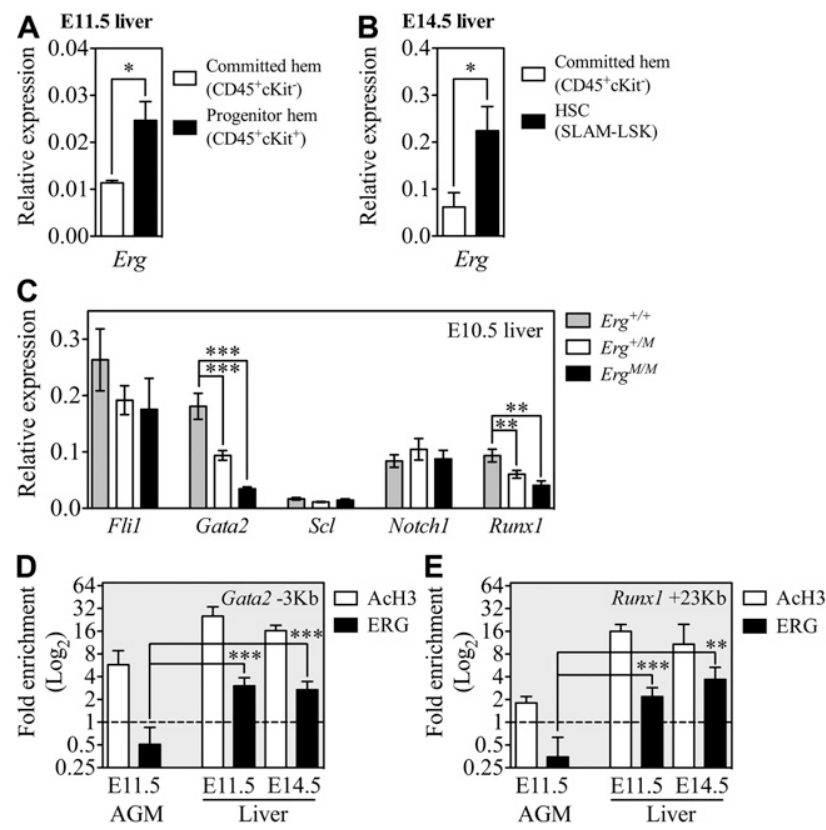

Figure 6. ERG directly regulates Runx1 and Gata2 expression. Using quantitative real-time PCR, levels of Erg mRNA expression were examined in purified lineage-committed $\left(\mathrm{CD} 45^{+} \mathrm{C}\right.$ $\mathrm{Kit}^{-}$or $\mathrm{Lin}^{+}$cells), progenitor-enriched $\left(\mathrm{CD} 45^{+} \mathrm{C}-\mathrm{Kit}^{+}\right)$, and HSC (SLAM-LSK) populations from E11.5 $(A)(n=3$ independent experiments) and E14.5 $(B)(n=3$ independent experiments $)$ $\mathrm{Erg}^{+/+}$fetal liver. $(C)$ Individual E10.5 livers from $\mathrm{Erg}^{+/+}(n=12)$, $\mathrm{Erg}^{+/ M}(n=14)$, and $\operatorname{Erg}^{M / M}(n=7)$ embryos were used to quantify expression of Fli1, Gata2, Scl, Notch1, and Runx1 mRNA. ChIP experiments were performed on nuclear preparations of $\mathrm{Erg}^{+/+}$ E11.5 AGM, whole E11.5 liver, or c-Kit ${ }^{+}$cells from E14.5 liver to investigate the direct binding of ERG to the Gata2 -3-kb $(D)$ and Runx $1+23-\mathrm{kb}(E)$ HSC enhancer elements. AcH3 ChIP was performed to examine whether these loci were transcriptionally active. Fold enrichment was relative to IgG controls. Data are cumulative of three to five independent experiments. $\left(^{\star}\right) P<$ $\left.0.05 ;\left(^{\star \star}\right) P<0.01 ;\left.\right|^{\star \star \star}\right) P<0.005$. 
Genetic targets of ERG have been described in prostate cancer cell lines (Yu et al. 2010), endothelial cell lines (Pimanda et al. 2006; Birdsey et al. 2008; Yuan et al. 2009), and hematopoietic cell lines (Rainis et al. 2005; Pimanda et al. 2007a); however, no physiological in vivo targets of ERG are known, particularly within the hematopoietic system. Both the Runx1 +27-kb and Gata2 -3-kb enhancer elements contain Ets-binding motifs (Nottingham et al. 2007; Pimanda et al. 2007b). To test if Gata2 and Runx1 are direct in vivo targets of ERG, we performed chromatin immunoprecipitation (ChIP) experiments to investigate whether ERG binds the Gata2 -3-kb and Runx1 +23-kb enhancer elements, which are active during hematopoietic development (Nottingham et al. 2007; Pimanda et al. 2007b). Using nuclear extracts from $\mathrm{Erg}^{+/+}$ whole E11.5 AGM, whole E11.5 fetal liver, and c-Kit ${ }^{+}$ E14.5 fetal liver cells, we performed ChIP experiments using anti-acetylated histone $3(\mathrm{AcH} 3)$ (to determine whether loci were transcriptionally active) and antiERG antibodies. The Gata2 -3-kb and Runx1 +23-kb enhancers were highly enriched by anti-AcH3 ChIP in the E11.5 AGM and fetal liver samples; however, significant enrichment following anti-ERG ChIP occurred only in the liver (Fig. 6D,E). These ChIP data suggest that, in the fetal liver but not in the AGM region, ERG functions as a crucial regulator of both Gata2 and Runx1 gene activity.

\section{Discussion}

In this study, we systematically explored the role of ERG during development of the hematopoietic system. Our data indicate that ERG is not required for hematopoietic specification to occur: In the $\operatorname{Erg}^{M / M}$ embryo, CFU-EryP were generated in the YS, primitive erythroid cells were observed in the embryonic peripheral circulation, and a full range of hematopoietic progenitors (CFU-Cs) was detected in both the YS and embryo proper of mutant embryos. Additionally, although $\operatorname{Erg}^{M / M}$ AGM regions failed to generate transplantable HSCs, IACs were formed, indicating that pre-HSC development did not require functional ERG. Using chimeras, we found that multiple hematopoietic lineages were generated, and secondary hematopoietic organs (fetal liver, thymus, and bone marrow) were engrafted by $\operatorname{Erg}^{M / M}$ hematopoietic cells, indicating that the initiation of definitive hematopoiesis was not ERG-dependent. Importantly, continued production of blood was found to be critically dependent on ERG and, by the end of the gestational period, almost no $\operatorname{Erg}^{M / M}$ hematopoietic cells could be found. Disappearance of differentiated blood cells from $\mathrm{Erg}^{+/ M}$ and $\mathrm{Erg}^{\mathrm{M} / M}$ chimeras was preceded by loss of HSCs, indicating that the primary function of ERG is to maintain the HSC pool. Consistent with current understanding, we presume that the $\operatorname{Erg}^{M / M}$ hematopoietic cells present in E14.5-E18.5 chimeras were produced by HSCs and thus represent ongoing definitive hematopoiesis. Therefore, ERG is not a regulator of hematopoietic specification or differentiation, but is required to sustain definitive hematopoiesis by preventing HSC exhaustion (Fig. 7); because we did not observe any signs of increased hematopoietic cell production (which would result from hyperproliferation) or increased apoptosis within $\mathrm{Erg}^{+/ M}$ or $\mathrm{Erg}^{M / M}$ progenitor populations, the underlying cause of exhaustion is likely the failure to effectively self-renew.

That the primary effect of Erg is at the level of HSC selfrenewal is further supported by the observation that maintenance of HSCs was dependent on ERG dose. Haploinsufficiency in $\mathrm{Erg}^{+/ M}$ HSCs was observed as early as E14.5, yet these HSCs persisted until at least E18.5 and continued to contribute to hematopoiesis. Between birth and adulthood, the deficiency in mutant cells allowed wild-type HSCs to dominate hematopoiesis in chimeras.

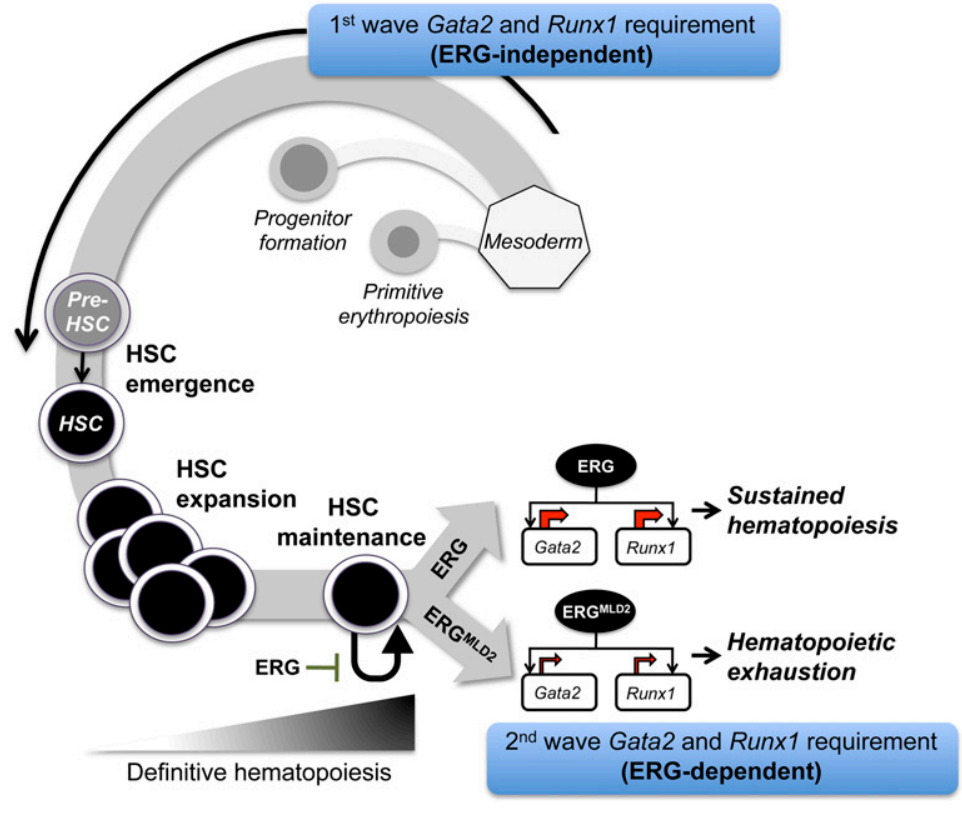

Figure 7. ERG is required to sustain definitive hematopoiesis. During early embryonic hematopoietic development, ERG is not required for hematopoietic specification from the mesoderm; thus, Erg ${ }^{\text {Mld2/Mld2 cells }}$ can undergo primitive erythropoiesis, progenitor formation, and HSC emergence (pre-HSC-to-HSC transition). These developmental pathways require a first wave of Gata2 and Runx1 expression; this is not dependent on ERG. Once definitive hematopoiesis is initiated, HSCs are required to execute maintaining self-renewals to preserve their numbers while contributing to hematopoiesis. At this point, ERG is critical and acts by controlling a second wave of Gata2 and Runx1 gene activity. In the absence of ERG (as in the case of the Erg ${ }^{\text {Mld2 }}$ embryo), HSCs are capable of contributing to hematopoiesis, but maintaining self-renewals are dysfunctional; thus, hematopoietic contribution is transient due to rapid HSC exhaustion. 
These data indicate that maintenance of HSCs was greatly impacted by the absence of ERG; it remains possible that expanding renewals are also ERG-dependent, as fewer $\operatorname{Erg}^{+/ M}$ and $\operatorname{Erg}^{M / M}$ HSCs were generated than observed from $\mathrm{Erg}^{+/+}$cells in the E14.5 chimera. The absence of a more exclusive HSC immunophenotype prior to E14.5 makes the study of earlier time points of HSC development problematic; as such, although HSC development could occur in the absence of functional ERG, it remains possible that, from the point of HSC emergence, ERG is required for normal function.

Our data provide an empirical explanation for why previous studies, which have knocked down Erg expression in embryonic zebrafish and mouse embryonic stem (ES) cells (Liu and Patient 2008; Nikolova-Krstevski et al. 2009), did not observe a hematopoietic defect. We found that ERG was indeed dispensable for early hematopoiesis, but once definitive hematopoiesis is initiated, ERG becomes critical. Modeling hematopoiesis using current ES protocols does not recapitulate definitive hematopoiesis (no HSCs are formed), and the early time points used to investigate $E r g$ knockdown in zebrafish did not examine the capacity to sustain definitive hematopoiesis, which requires long-term tracking. These studies most likely reflect the dispensable role of ERG during hematopoietic specification.

We demonstrated that the E11.5 AGM region pre-HSC population expressed relatively high levels of Erg, comparable with expression in the endothelial component of the organ; however, the existence of HSCs in the E14.5 chimeric liver indicated that, in the absence of functional ERG, the pre-HSC-to-HSC transition could occur. At E14.5, HSCs express relatively low levels of Erg, but this is significantly higher than in lineage-committed hematopoietic cells, suggesting that, within the hematopoietic lineage, ERG is preferentially required for HSC function.

We presented the first mechanistic insight into the regulation of hematopoiesis by ERG. We showed that, in vivo, ERG is a direct positive regulator of Gata2 and Runx1 gene activity: Both genes exhibited ERG occupancy at enhancer sequences in the fetal liver and, in the absence of functional ERG, expression of both Gata2 and Runx1 was significantly reduced. Because, within the hematopoietic component of the E11.5 AGM region, only the rare VE-cadherin ${ }^{+} \mathrm{CD} 45^{+}$cells express high levels of ERG, it is possible that Gata2 and Runx1 enhancer sequences were bound but their relative expression was too low to be effectively detected within the heterogeneous cellular composition of whole AGM. These data provide an interesting conceptual insight: Failure of HSC maintenance-caused by mutation of Erg and hence diminished expression Gata2 and Runx1-suggests that these essential regulators of hematopoietic specification are cooperatively required later in development to control HSC self-renewal. Of note, a heterozygous dose of either Gata2 or Runx1 alters the temporal and/or spatial pattern of HSC emergence but does not affect the function of the HSCs produced (Cai et al. 2000; North et al. 2002; Ling et al. 2004). Our observations indicate a secondary and cooperative role for GATA2 and RUNX1 beyond initia- tion of hematopoiesis-this pathway is directly regulated by ERG. Interestingly, it has been reported recently that GATA2 and RUNX1 are capable of interacting at the protein level; Wilson et al. (2010) also reported that compound Runx1 $1^{+--}:$Gata2 $^{+/-}$fetal livers contain fewer progenitors and the embryos die between E12.5 and birth. Identifying the targets of GATA2/RUNX1-containing complexes in HSCs will likely be of great interest.

In summary, our findings show that hematopoietic progenitor generation, HSC formation, and the initiation of definitive hematopoiesis can occur without functional ERG; however, ERG is a critical early regulator of HSC maintenance, such that preservation of definitive hematopoiesis as a self-sustaining hierarchy becomes ERGdependent during fetal life.

\section{Materials and methods}

\section{Mice}

All mice were maintained on a C57BL/ 6 background. Generation of Erg ${ }^{\text {Mld2 }}$ mice has been described previously (Loughran et al. 2008). UBl-GFP mice were purchased from Jackson Laboratories (Schaefer et al. 2001). Erg $^{+/ M 1 d 2}$ :UBI-GFP mice were generated by intercross of $\mathrm{Erg}^{+/ M I d 2}$ and $\mathrm{UBl}^{+/ G F P}$ mice. Embryos were generated by timed mating; the morning of a positive plug check was considered E0.5. Experimental procedures were approved by the Walter and Eliza Hall Institute Animal Ethics Committee.

$\operatorname{Erg}^{\text {Mld2 }}$ genotyping

DNA lysates for genotyping were prepared using DirectPCR Reagent (Viagen Biotech) according to the manufacturer's instructions. Mld2 genotyping was performed using TaqMan genotyping probes (purchased from Applied Biosystems).

\section{Embryology}

Between E8 and E9, developmental stage was established by counting somite pairs; from E10 onward, developmental stage was established according to Theiler's criteria. E8.5 embryo proper and E8.5-E11.5 YS were dissected using watchmakers' forceps. Between E9.5 and E11.5, P-Sp, AGM, and liver were dissected and dissociated as described previously (Medvinsky et al. 2008). Placenta was prepared as described previously (Gekas et al. 2008). Flow cytometry was performed using VE-cadherin (BV13), CD45 (30-F11), and CD41 (MWreg30) antibodies (purchased from eBioscience and BD Biosciences). Dead cells were excluded according to 7-AAD staining. Gate placement was determined by isotype controls.

\section{Clonogenic progenitor assay}

Single-cell preparations were cultured in complete methylcellulose-based medium (M3434, Stem Cell Technologies). Colonies were scored after $8 \mathrm{~d}$ as described previously (Medvinsky et al. 2008).

\section{In situ hybridization}

cRNA probes were generated by in vitro transcription. Ergspecific probes were generated from the 1.4-kb Erg coding region. Hybridization of cRNA probes and visualization of staining were performed as described previously (Thomas et al. 2007). 


\section{Organ explant}

E10.5-E11.5 AGM regions were cultured as explants at the gasliquid interface as described previously (Taoudi et al. 2008), with the exception that newborn calf serum was used (Hyclone). Organs from each embryo were cultured in separate wells. After $4 \mathrm{~d}$, organs were dissociated as described previously (Taoudi et al. 2005).

\section{Long-term repopulation assay}

Recipient adult mice (8-12 wk old) were exposed to 950-rad split dose $(2 \times 450 \mathrm{rad}$ separated by $3 \mathrm{~h})$ of $\gamma$-radiation. The appropriate embryo equivalent was cotransplanted with 50,000 spleen cells. The distinction between donor, recipient, and carrier cells was made using the Ly5/CD45 isoform system: Donor cells were Ly5.2, and recipient and carrier cells were Ly5.1 (distinguished by flow cytometry|. Mice were considered reconstituted with $\geq 5 \%$ Ly5.2 (donor) contribution to multilineage reconstitution after $16 \mathrm{wk}$.

\section{Chimera analysis}

Embryo chimeras were generated by morula aggregation as described previously (Nagy et al. 2003). In brief, E2.5 $\mathrm{Erg}^{+/+}$ GFP-negative morulae were aggregated with morulae generated by $\mathrm{Erg}^{+/ M l d 2}$ :UBl-GFP intercross (embryos were screened for GFP fluorescence prior to aggregation). Chimeras were analyzed at E14.5, E18.5, or adulthood (6-10 wk). Nonhematopoietic adult organs were dissected; GFP fluorescence was imaged using a Leica MZ6 fluorescence microscope. Flow cytometric analysis of mature hematopoietic lineages was performed as described previously (Taoudi et al. 2005). Antibodies for the following markers were used to identify HSCs: E14.5-E18.5 = Ter119, B220, CD19, CD3e, CD4, CD8, CD48, CD41 (Lineage)-PE (BD Biosciences); CD150-APC (Biolegend); c-Kit-biotin (BD Biosciences); Sca1-PE-Cy7 (BD Biosciences). Adult HSCs were detected as above, with the exception that Macl antibody was included in the lineage cocktail. Biotin was detected with streptavidinqdot605 (Invitrogen).

\section{Chimeric fibroblast derivation}

Murine embryonic fibroblasts (MEFs) were generated from E14.5 chimeras by pipetting disrupted carcasses in $1 \mathrm{~mL}$ of fibroblast medium (10\% FCS/DMEM) and were transferred to a $25-\mathrm{cm}^{3}$ tissue culture flask. Tail tip fibroblasts were generated from tail tip explants on gelatin-coated six-well plates in fibroblast medium. $\mathrm{GFP}^{+}$fibroblasts were purified by flow cytometry. Genotyping of purified fibroblast was performed as described above.

\section{Quantitative real-time PCR}

Total RNA was extracted from E10.5 fetal liver using the RNeasy micro kit (Qiagen). cDNA was prepared using the First Strand synthesis kit (Invitrogen). PCR primers were purchased from Applied Biosystems (Hmbs-1, Erg, Fli1, Runx1, Gata2, Scl, and Notch1). Expression was calculated using the $\Delta \mathrm{CT}$ method relative to Hmbs-1.

\section{ChIP}

Nuclear extracts were prepared from whole E11.5 AGM and E11.5 liver. For E14.5 fetal liver, nuclear extracts were prepared from MACS-purified (Miltenyi Biotec) c-Kit ${ }^{+}$populations (these cells contained $91 \% \pm 0.9 \% \mathrm{c}-\mathrm{Kit}^{+}$cells and $51 \% \pm 2 \% \mathrm{CD}^{+} 5^{+}$ cells). ChIP was performed using anti-AcH3 (ChIP-grade; Millipore/Upstate Biotechnologies, 06-599), anti-ERG (Santa Cruz Biotechnology, sc354X; used previously for ChIP) (Pimanda et al. 2006; Wilson et al. 2010), and IgG control (Sigma, 15006) antibodies. ChIP conditions were performed as described previously (Pimanda et al. 2006). Primers for Runx1 +23-kb (F-AAG CTGCCCACGTTATCAGT; R-CAGATGGAGGCATCCTGTTT) and Gata2 -3-kb (F-GCGGATCTGTGGTGGTAAAT; R-TGTA CAGGGCTGGGAATTGT) enhancer sequences were purchased from Invitrogen.

\section{Statistical analysis}

All data in the text are described as mean \pm standard deviation (SD). Statistical analyses were performed using the unpaired twotailed Student's $t$-test. Prism software (GraphPad) was used to prepare graphs and perform statistical analyses. Differences were considered significant if $P$-values were $<0.05$ compared with wild-type controls.

\section{Acknowledgments}

We thank Dr. Ashley Ng for practical assistance and critical discussions, and WEHI services for assistance with animal husbandry, cell sorting, mouse irradiation, and histological preparation of samples. We also thank Dr. Julie Sheridan and Dr. Christele Gonneau for critical comments on the manuscript. This work was supported by a Program grant (461219), Project grant (516726, 510100, 568668), Fellowships (to D.J.H., W.S.A., A.K.V., and B.T.K.) and Independent Research Institutes Support Scheme grant (361646) from the Australian National Health and Medical Research Council of Australia (NHMRC); the Australian Cancer Research Foundation; Australian Stem Cell Centre collaborative stream grant (adult stem cells, module 8); a Fellowship from the Australian Research Council (to B.T.K.); a Fellowship from the Sylvia and Charles Viertel Charitable Foundation (to B.T.K.); and a Victorian State Government Operational Infrastructure Support grant.

\section{References}

Bertrand JY, Giroux S, Golub R, Klaine M, Jalil A, Boucontet L, Godin I, Cumano A. 2005. Characterization of purified intraembryonic hematopoietic stem cells as a tool to define their site of origin. Proc Natl Acad Sci 102: 134-139.

Birdsey GM, Dryden NH, Amsellem V, Gebhardt F, Sahnan K, Haskard DO, Dejana E, Mason JC, Randi AM. 2008. Transcription factor Erg regulates angiogenesis and endothelial apoptosis through VE-cadherin. Blood 111: 3498-3506.

Boisset JC, van Cappellen W, Andrieu-Soler C, Galjart N, Dzierzak E, Robin C. 2010. In vivo imaging of haematopoietic cells emerging from the mouse aortic endothelium. Nature 464: 116-120.

Cai Z, de Bruijn M, Ma X, Dortland B, Luteijn T, Downing RJ, Dzierzak E. 2000. Haploinsufficiency of AML1 affects the temporal and spatial generation of hematopoietic stem cells in the mouse embryo. Immunity 13: 423-431.

Chan WY, Follows GA, Lacaud G, Pimanda JE, Landry JR, Kinston S, Knezevic K, Piltz S, Donaldson IJ, Gambardella L, et al. 2007. The paralogous hematopoietic regulators Lyll and $\mathrm{Scl}$ are coregulated by Ets and GATA factors, but Lyll cannot rescue the early $\mathrm{Scl}^{-1-}$ phenotype. Blood 109: 1908-1916.

Chen MJ, Yokomizo T, Zeigler BM, Dzierzak E, Speck NA. 2009. Runx1 is required for the endothelial to haematopoietic cell transition but not thereafter. Nature 457: 887891. 
Christensen JL, Wright DE, Wagers AJ, Weissman IL. 2004. Circulation and chemotaxis of fetal hematopoietic stem cells. PLOS Biol 2: e75. doi: 10.1371/journal.pbio.0020075.

Corbel C, Vaigot P, Salaun J. 2005. $\alpha$ IIb integrin, a novel marker for hemopoietic progenitor cells. Int J Dev Biol 49: 279-284.

de Bruijn MF, Speck NA, Peeters MC, Dzierzak E. 2000. Definitive hematopoietic stem cells first develop within the major arterial regions of the mouse embryo. EMBO $J$ 19: $2465-2474$

Ema H, Nakauchi H. 2000. Expansion of hematopoietic stem cells in the developing liver of a mouse embryo. Blood 95: 2284-2288.

Gekas C, Dieterlen-Lievre F, Orkin SH, Mikkola HK. 2005. The placenta is a niche for hematopoietic stem cells. Dev Cell 8: 365-375.

Gekas C, Rhodes KE, Mikkola HK. 2008. Isolation and visualization of mouse placental hematopoietic stem cells. Curr Protoc Stem Cell Biol 6: 2A.8.1-2A.8.14. doi: 10.1002/ 9780470151808.sc02a08s6.

Hadland BK, Huppert SS, Kanungo J, Xue Y, Jiang R, Gridley T, Conlon RA, Cheng AM, Kopan R, Longmore GD. 2004. A requirement for Notch1 distinguishes 2 phases of definitive hematopoiesis during development. Blood 104: 3097-3105.

Hart A, Melet F, Grossfeld P, Chien K, Jones C, Tunnacliffe A, Favier R, Bernstein A. 2000. Fli-1 is required for murine vascular and megakaryocytic development and is hemizygously deleted in patients with thrombocytopenia. Immunity 13: 167-177.

Ichikawa M, Asai T, Saito T, Seo S, Yamazaki I, Yamagata T, Mitani K, Chiba S, Ogawa S, Kurokawa M, et al. 2004. AML1 is required for megakaryocytic maturation and lymphocytic differentiation, but not for maintenance of hematopoietic stem cells in adult hematopoiesis. Nat Med 10: 299-304.

Kiel MJ, Yilmaz OH, Iwashita $\mathrm{T}$, Yilmaz OH, Terhorst C, Morrison SJ. 2005. SLAM family receptors distinguish hematopoietic stem and progenitor cells and reveal endothelial niches for stem cells. Cell 121: 1109-1121.

Kiel MJ, Yilmaz OH, Morrison SJ. 2008. CD150- cells are transiently reconstituting multipotent progenitors with little or no stem cell activity. Blood 111: 4413-4415.

Kim I, He S, Yilmaz OH, Kiel MJ, Morrison SJ. 2006. Enhanced purification of fetal liver hematopoietic stem cells using SLAM family receptors. Blood 108: 737-744.

Kim I, Saunders TL, Morrison SJ. 2007. Sox17 dependence distinguishes the transcriptional regulation of fetal from adult hematopoietic stem cells. Cell 130: 470-483.

Kumano K, Chiba S, Kunisato A, Sata M, Saito T, NakagamiYamaguchi E, Yamaguchi T, Masuda S, Shimizu K, Takahashi T, et al. 2003. Notch1 but not Notch2 is essential for generating hematopoietic stem cells from endothelial cells. Immunity 18: 699-711.

Kumaravelu P, Hook L, Morrison AM, Ure J, Zhao S, Zuyev S, Ansell J, Medvinsky A. 2002. Quantitative developmental anatomy of definitive haematopoietic stem cells/long-term repopulating units (HSC/RUs): Role of the aorta-gonadmesonephros (AGM) region and the yolk sac in colonisation of the mouse embryonic liver. Development 129: 4891-4899.

Landry JR, Kinston S, Knezevic K, de Bruijn MF, Wilson N, Nottingham WT, Peitz M, Edenhofer F, Pimanda JE, Ottersbach $\mathrm{K}$, et al. 2008. Runx genes are direct targets of Scl/Tall in the yolk sac and fetal liver. Blood 111: 3005-3014.

Ling KW, Ottersbach K, van Hamburg JP, Oziemlak A, Tsai FY, Orkin SH, Ploemacher R, Hendriks RW, Dzierzak E. 2004. GATA-2 plays two functionally distinct roles during the ontogeny of hematopoietic stem cells. J Exp Med 200: 871882 .
Liu F, Patient R. 2008. Genome-wide analysis of the zebrafish ETS family identifies three genes required for hemangioblast differentiation or angiogenesis. Circ Res 103: 1147-1154.

Loughran SJ, Kruse EA, Hacking DF, de Graaf CA, Hyland CD, Willson TA, Henley KJ, Ellis S, Voss AK, Metcalf D, et al. 2008. The transcription factor Erg is essential for definitive hematopoiesis and the function of adult hematopoietic stem cells. Nat Immunol 9: 810-819.

Mancini SJ, Mantei N, Dumortier A, Suter U, MacDonald HR, Radtke F. 2005. Jagged1-dependent Notch signaling is dispensable for hematopoietic stem cell self-renewal and differentiation. Blood 105: 2340-2342.

Masuya M, Moussa O, Abe T, Deguchi T, Higuchi T, Ebihara Y, Spyropoulos DD, Watson DK, Ogawa M. 2005. Dysregulation of granulocyte, erythrocyte, and NK cell lineages in Fli-1 gene-targeted mice. Blood 105: 95-102.

McKinney-Freeman SL, Naveiras O, Yates F, Loewer S, Philitas M, Curran M, Park PJ, Daley GQ. 2009. Surface antigen phenotypes of hematopoietic stem cells from embryos and murine embryonic stem cells. Blood 114: 268-278.

Medvinsky A, Dzierzak E. 1996. Definitive hematopoiesis is autonomously initiated by the AGM region. Cell 86: 897906.

Medvinsky A, Taoudi S, Mendes S, Dzierzak E. 2008. Analysis and manipulation of hematopoietic progenitor and stem cells from murine embryonic tissues. Curr Protoc Stem Cell Biol 4: 2A.6.1-2A.6.25. doi: 10.1002/9780470151808.sc02a06s4.

Mikkola HK, Klintman J, Yang H, Hock H, Schlaeger TM, Fujiwara Y, Orkin SH. 2003. Haematopoietic stem cells retain long-term repopulating activity and multipotency in the absence of stem-cell leukaemia SCL/tal-1 gene. Nature 421: 547-551.

Nagy A, Gertsenstein M, Vintersten K, Behringer R. 2003. Manipulating the mouse embryo: A laboratory manual. Cold Spring Harbor Laboratory Press, Cold Spring Harbor, NY.

Nikolova-Krstevski V, Yuan L, Le Bras A, Vijayaraj P, Kondo M, Gebauer I, Bhasin M, Carman CV, Oettgen P. 2009. ERG is required for the differentiation of embryonic stem cells along the endothelial lineage. BMC Dev Biol 9: 72. doi: 10.1186/ 1471-213X-9-72.

North TE, de Bruijn MF, Stacy T, Talebian L, Lind E, Robin C, Binder M, Dzierzak E, Speck NA. 2002. Runx1 expression marks long-term repopulating hematopoietic stem cells in the midgestation mouse embryo. Immunity 16: 661-672.

Nottingham WT, Jarratt A, Burgess M, Speck CL, Cheng JF, Prabhakar S, Rubin EM, Li PS, Sloane-Stanley J, Kong ASJ, et al. 2007. Runx1-mediated hematopoietic stem-cell emergence is controlled by a Gata/Ets/SCL-regulated enhancer. Blood 110: 4188-4197.

Okuda T, van Deursen J, Hiebert SW, Grosveld G, Downing JR. 1996. AML1, the target of multiple chromosomal translocations in human leukemia, is essential for normal fetal liver hematopoiesis. Cell 84: 321-330.

Pimanda JE, Chan WY, Donaldson IJ, Bowen M, Green AR, Gottgens B. 2006. Endoglin expression in the endothelium is regulated by Fli-1, Erg, and Elf-1 acting on the promoter and a -8 -kb enhancer. Blood 107: 4737-4745.

Pimanda JE, Donaldson IJ, de Bruijn MF, Kinston S, Knezevic K, Huckle L, Piltz S, Landry JR, Green AR, Tannahill D, et al. 2007a. The SCL transcriptional network and BMP signaling pathway interact to regulate RUNX1 activity. Proc Natl Acad Sci 104: 840-845.

Pimanda JE, Ottersbach K, Knezevic K, Kinston S, Chan WY, Wilson NK, Landry JR, Wood AD, Kolb-Kokocinski A, Green AR, et al. 2007b. Gata2, Fli1, and Scl form a recursively 
wired gene-regulatory circuit during early hematopoietic development. Proc Natl Acad Sci 104: 17692-17697.

Porcher C, Swat W, Rockwell K, Fujiwara Y, Alt FW, Orkin SH. 1996. The T cell leukemia oncoprotein SCL/tal-1 is essential for development of all hematopoietic lineages. Cell 86: 4757.

Rainis L, Toki T, Pimanda JE, Rosenthal E, Machol K, Strehl S, Gottgens B, Ito E, Izraeli S. 2005. The proto-oncogene ERG in megakaryoblastic leukemias. Cancer Res 65: 7596-7602.

Robert-Moreno A, Espinosa L, de la Pompa JL, Bigas A. 2005. RBPjк-dependent Notch function regulates Gata2 and is essential for the formation of intra-embryonic hematopoietic cells. Development 132: 1117-1126.

Robert-Moreno A, Guiu J, Ruiz-Herguido C, Lopez ME, InglesEsteve J, Riera L, Tipping A, Enver T, Dzierzak E, Gridley T, et al. 2008. Impaired embryonic haematopoiesis yet normal arterial development in the absence of the Notch ligand Jagged1. EMBO I 27: 1886-1895.

Schaefer BC, Schaefer ML, Kappler JW, Marrack P, Kedl RM. 2001. Observation of antigen-dependent $\mathrm{CD}^{+} \mathrm{T}$-cell/dendritic cell interactions in vivo. Cell Immunol 214: 110-122.

Schlaeger TM, Mikkola HK, Gekas C, Helgadottir HB, Orkin SH. 2005. Tie2Cre-mediated gene ablation defines the stemcell leukemia gene (SCL/tall)-dependent window during hematopoietic stem-cell development. Blood 105: 38713874.

Shivdasani RA, Mayer EL, Orkin SH. 1995. Absence of blood formation in mice lacking the T-cell leukaemia oncoprotein tal-1/SCL. Nature 373: 432-434.

Spyropoulos DD, Pharr PN, Lavenburg KR, Jackers P, Papas TS, Ogawa M, Watson DK. 2000. Hemorrhage, impaired hematopoiesis, and lethality in mouse embryos carrying a targeted disruption of the Flil transcription factor. Mol Cell Biol 20: 5643-5652.

Taoudi S, Medvinsky A. 2007. Functional identification of the hematopoietic stem cell niche in the ventral domain of the embryonic dorsal aorta. Proc Natl Acad Sci 104: 9399-9403.

Taoudi S, Morrison AM, Inoue H, Gribi R, Ure J, Medvinsky A. 2005. Progressive divergence of definitive haematopoietic stem cells from the endothelial compartment does not depend on contact with the foetal liver. Development 132: 4179-4191.

Taoudi S, Gonneau C, Moore K, Sheridan JM, Blackburn CC, Taylor E, Medvinsky A. 2008. Extensive hematopoietic stem cell generation in the AGM region via maturation of VEcadherin ${ }^{+} \mathrm{CD} 45^{+}$pre-definitive HSCs. Cell Stem Cell 3: 99108.

Thomas T, Corcoran LM, Gugasyan R, Dixon MP, Brodnicki T, Nutt SL, Metcalf D, Voss AK. 2006. Monocytic leukemia zinc finger protein is essential for the development of longterm reconstituting hematopoietic stem cells. Genes Dev 20: $1175-1186$.

Thomas T, Loveland KL, Voss AK. 2007. The genes coding for the MYST family histone acetyltransferases, Tip60 and Mof are expressed at high levels during sperm development. Gene Expr Patterns 7: 657-665.

Tsai FY, Keller G, Kuo FC, Weiss M, Chen J, Rosenblatt M, Alt FW, Orkin SH. 1994. An early haematopoietic defect in mice lacking the transcription factor GATA-2. Nature 371: 221226.

Wang Q, Stacy T, Binder M, Marin-Padilla M, Sharpe AH, Speck NA. 1996. Disruption of the Cbfa2 gene causes necrosis and hemorrhaging in the central nervous system and blocks definitive hematopoiesis. Proc Natl Acad Sci 93: 3444-3449.

Wilson NK, Miranda-Saavedra D, Kinston S, Bonadies N, Foster SD, Calero-Nieto F, Dawson MA, Donaldson IJ, Dumon S,
Frampton J, et al. 2009. The transcriptional program controlled by the stem cell leukemia gene Scl/Tall during early embryonic hematopoietic development. Blood 113: 54565465.

Wilson NK, Foster SD, Wang X, Knezevic K, Schutte J, Kaimakis P, Chilarska PM, Kinston S, Ouwehand WH, Dzierzak E, et al. 2010. Combinatorial transcriptional control in blood stem/progenitor cells: Genome-wide analysis of ten major transcriptional regulators. Cell Stem Cell 7: 532-544.

Yu J, Mani RS, Cao Q, Brenner CJ, Cao X, Wang X, Wu L, Li J, Hu $\mathrm{M}$, Gong $\mathrm{Y}$, et al. 2010. An integrated network of androgen receptor, polycomb, and TMPRSS2-ERG gene fusions in prostate cancer progression. Cancer Cell 17: 443-454.

Yuan L, Nikolova-Krstevski V, Zhan Y, Kondo M, Bhasin M, Varghese L, Yano K, Carman CV, Aird WC, Oettgen P. 2009. Antiinflammatory effects of the ETS factor ERG in endothelial cells are mediated through transcriptional repression of the interleukin-8 gene. Circ Res 104: 1049-1057. 


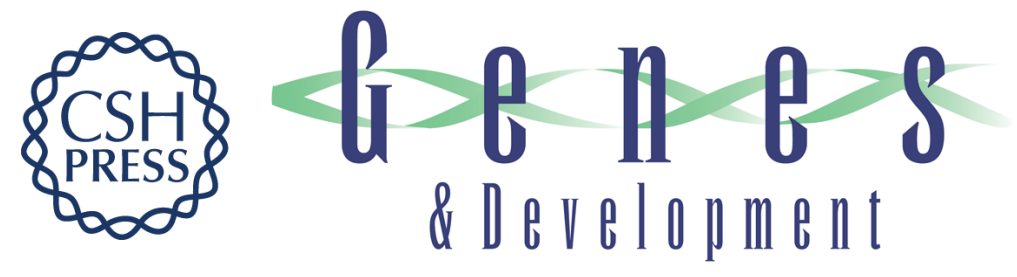

\section{ERG dependence distinguishes developmental control of hematopoietic stem cell maintenance from hematopoietic specification}

Samir Taoudi, Thomas Bee, Adrienne Hilton, et al.

Genes Dev. 2011, 25: originally published online January 18, 2011

Access the most recent version at doi:10.1101/gad.2009211

\section{Supplemental http://genesdev.cshlp.org/content/suppl/2011/01/11/gad.2009211.DC1 \\ Material}

Related Content The ERGonomics of hematopoietic stem cell self-renewal

Scott A. Lacadie and Leonard I. Zon

Genes Dev. February , 2011 25: 289-293

References This article cites 57 articles, 29 of which can be accessed free at:

http://genesdev.cshlp.org/content/25/3/251.full.html\#ref-list-1

Articles cited in:

http://genesdev.cshlp.org/content/25/3/251.full.html\#related-urls

\section{License}

Email Alerting

Service

Receive free email alerts when new articles cite this article - sign up in the box at the top right corner of the article or click here.

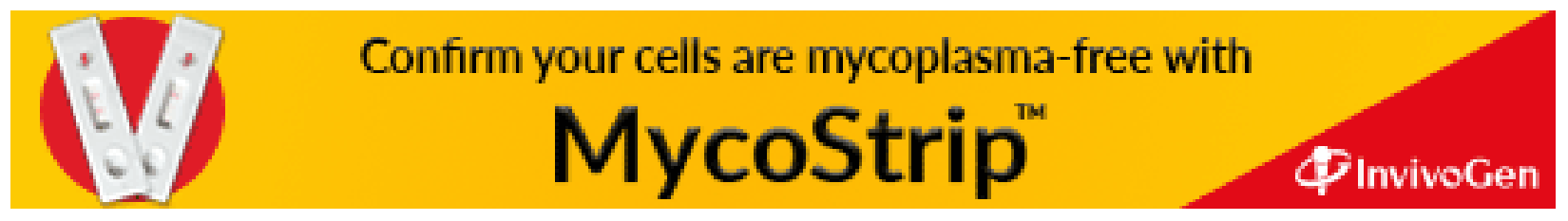

